\title{
Tagung der Gesellschaft für Verdauungs- und
}

\section{Stoffwechselkrankheiten}

Vom 4.-7. Oktober findet die diesjährige Tagung in Wien in der Hofburg statt. Es werden folgende Themata abgehandelt:

4. Oktober: ßeaktions- und Osmo-Regulation des Stoffwe $<1 / 8$ sels.

Referenten: íföfter-Kiel, Porges-Wien, von ivorany ¿-Budapest, ß $\alpha \mathrm{Zm} /$-Budapest.

5. Oktober: Ileus (Wegstöruiiííen des Darmes).

Referenten: Tandler-Wien, iíafccñ-Frankfurt a. M., Gottwald Schwarz-Wien, von den VeMenBerlin, Brcmrt-Berlin.

6. Oktober: Steinbildung.

Referenten: von Fürth-Wien, Herxheimer-Wiesbaden, Erich Meyer-Göttingen, Holzknecht-

Wien, Berg-Berlin, Schinz-Zürich, Forsell-Stockholm.

7. Oktober: Diabetes.

Referenten: Otto Ló1/8z-Graz, Falta-Wien, S1/8uf > -Basel.

Der Kongreß ist von den Medizinischen Fakultäten von Budapest und Pécs (Fünfkirchen) eingeladen, in Fortsetzung seiner Tagung die Einrichtungen der beiden Fakultäten zu besichtigen (8.-10. Oktober).

Mit der Tagung ist eine Ausstellung pharmazeutischer Präparate usw. verbunden.

Näheres durch das Generalsekretariat: Prof, von den Velden, Berlin W 30, Bamberger Str. 49. 